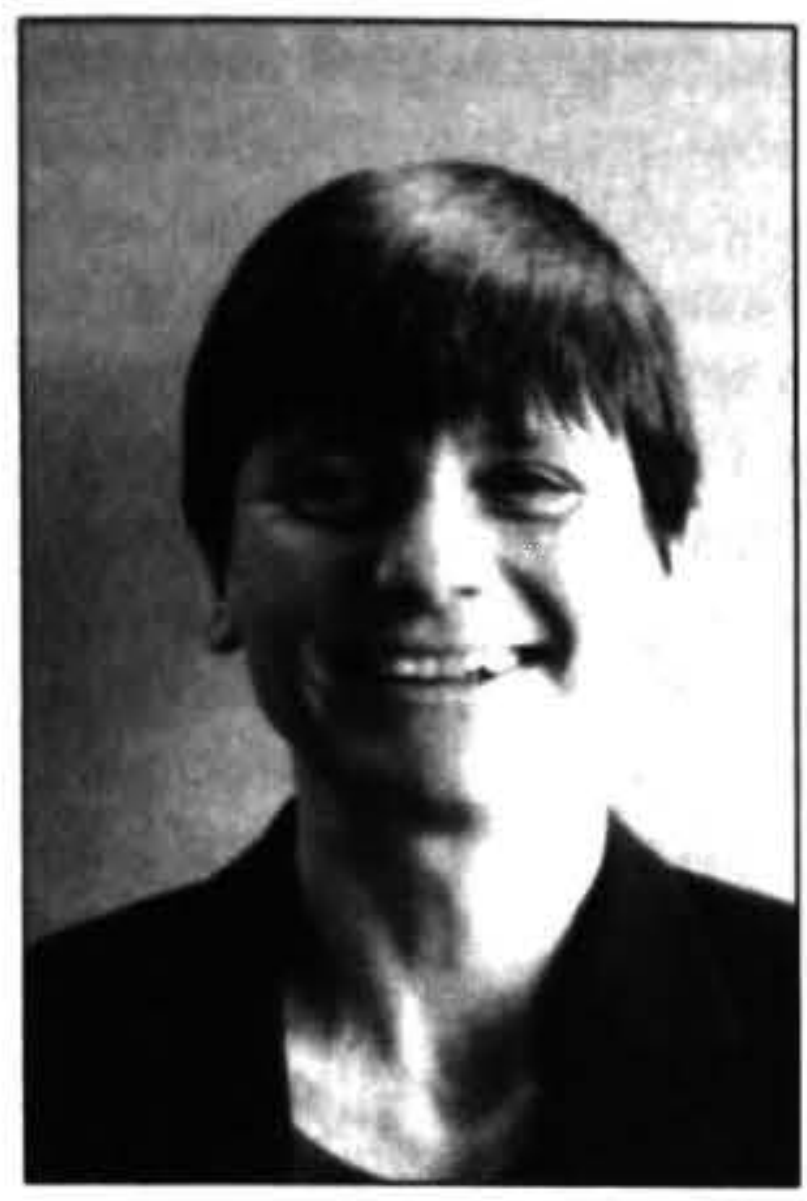

\title{
LABOUR MARKET TRENDS AND OUTLOOK
}

\author{
Joselyn Stroombergen \\ Work Directions, \\ Department of Labour, Wellington
}

\begin{abstract}
Given New Zealand's recent robust economic performance, 3.6\% per annum on average since 1999. the strong improvement in a wide array of labour market indicators has not been surprising. What has surprised many economic commentators has been the continued strength of the labour market in the face of the recent slowing economic activity.

The ability of the economy to make use of its labour capacity may have improved suggesting a fall in New' Zealand's non-accelerating inflation rate of unemployment (NAIRU).

With labour utilisation now stretched to the limit, if we want to maintain economic growth at levels we have become accustomed to, we will need to substantially lift the level of labour productivity growth in the coming vears. However. making the transition to a more productive economy while maintaining the gains we have achieved in labour utilisation will not be an easy task.
\end{abstract}

\section{Introduction}

The labour market is a key part of the economy. Put simply, over the long run, economic growth depends on increases in two things: the utilisation and productivity of labour (Figure 1).

New Zealand's recent robust economic performance, $3.6 \%$ per annum on average since 1999 , has primarily been driven by a strong increase in labour utilisation. The working age population has grown by some 297,000 people with a contribution of over 20,000 per annum from net permanent and long-term migration in the past 5 years. The labour force participation rate has risen to its highest ever rate. In the year to September 2006, 68.4\% of those people aged 15 years and over were classified as in the labour force, with $96.3 \%$ of those in employment and only $3.7 \%$ officially unemployed. In fact, unemployment has fallen to 20-year lows and at times (for example, in 2005) New Zealand has had the lowest unemployment rate in the OECD. Although average hours worked has been falling recently, New Zealanders are still working some of the longest hours in the OECD.

Despite this impressive labour market performance, there are still a number of challenges ahead if we want to lift the real incomes of all New Zealanders and return New Zealand's real per capita income to the top half of the OECD rankings.
Figure 1: Contributions to Growth.

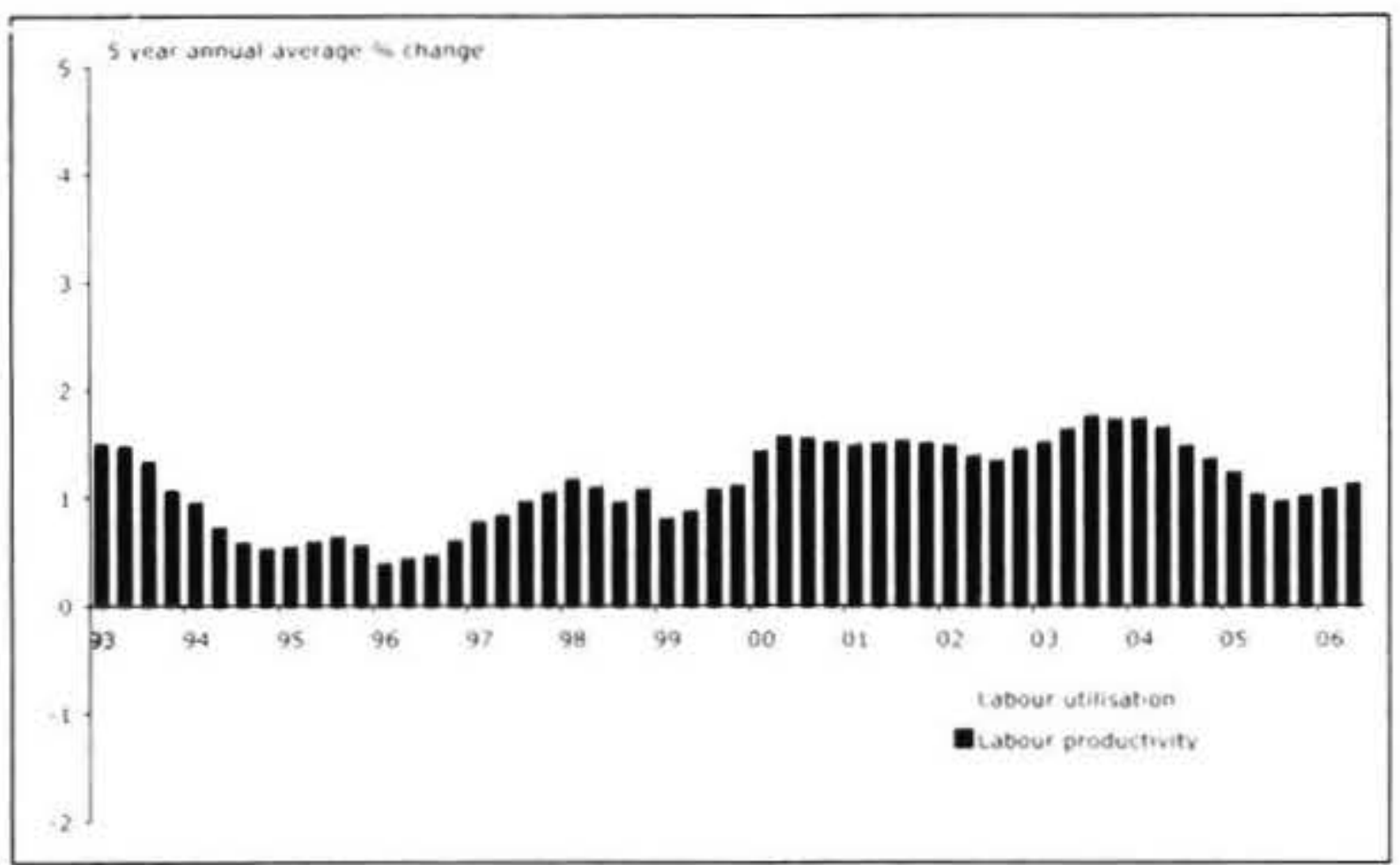

Source: Statistics New Zealand. DoL calculations

Labour productivity growth has been only modest in recent years and although not entirely unexpected given the strong increase in labour utilisation', we will need to lift the level of labour productivity growth in the coming years if we want to maintain economic growth and lift our standard of living. Employees can work longer hours or more people can enter the labour force, but only for so long. However, higher labour productivity growth can deliver compound growth in incomes from whatever level of labour utilisation is achieved, year after year. Productivity growth feeds directly into business profitability and is the key to sustained wage growth without inflationary pressure. 
However, making the transition to a more productive economy while maintaining the gains we have achieved in labour utilisation will not be an easy task. A quick look around us suggests that the fall in New Zealand's unemployment rate to below $4 \%$ has pushed wage inflation to a pace that is inconsistent with our inflation target.

The rate of unemployment that the economy can sustain without a marked increase in wage or price pressure is commonly referred as the NAIRU - or non-accelerating inflation rate of unemployment. While estimation of the NAIRU is imprecise as it cannot be observed directly, we are reasonably confident that the ability of the New Zealand economy to make use of its existing labour capacity without getting overheated has improved recently - thereby leading to a fall in our NAIRU.

This paper examines recent trends in the demand for, and supply of, labour. It also examines some of the factors that may have led to a positive structural change in the labour market and a fall in New Zealand's NAIRU.

\section{Labour Supply}

\section{Population}

The population represents our potential labour supply: hence it feeds directly into labour utilisation. In New Zealand, year to year changes in population tend to be dominated by migration flows with changes due to natural increase (births minus deaths) reasonably steady (averaging just under 30,000 per annum over the past 10 years). With a long-term average of around 10,000 , net permanent and long-term migration flows have fluctuated from a high of 42.500 in the year ended June 2003 to a low of $-11,400$ in the year ended June 1999 (Figure 2).

Figure 2: Population Growth.

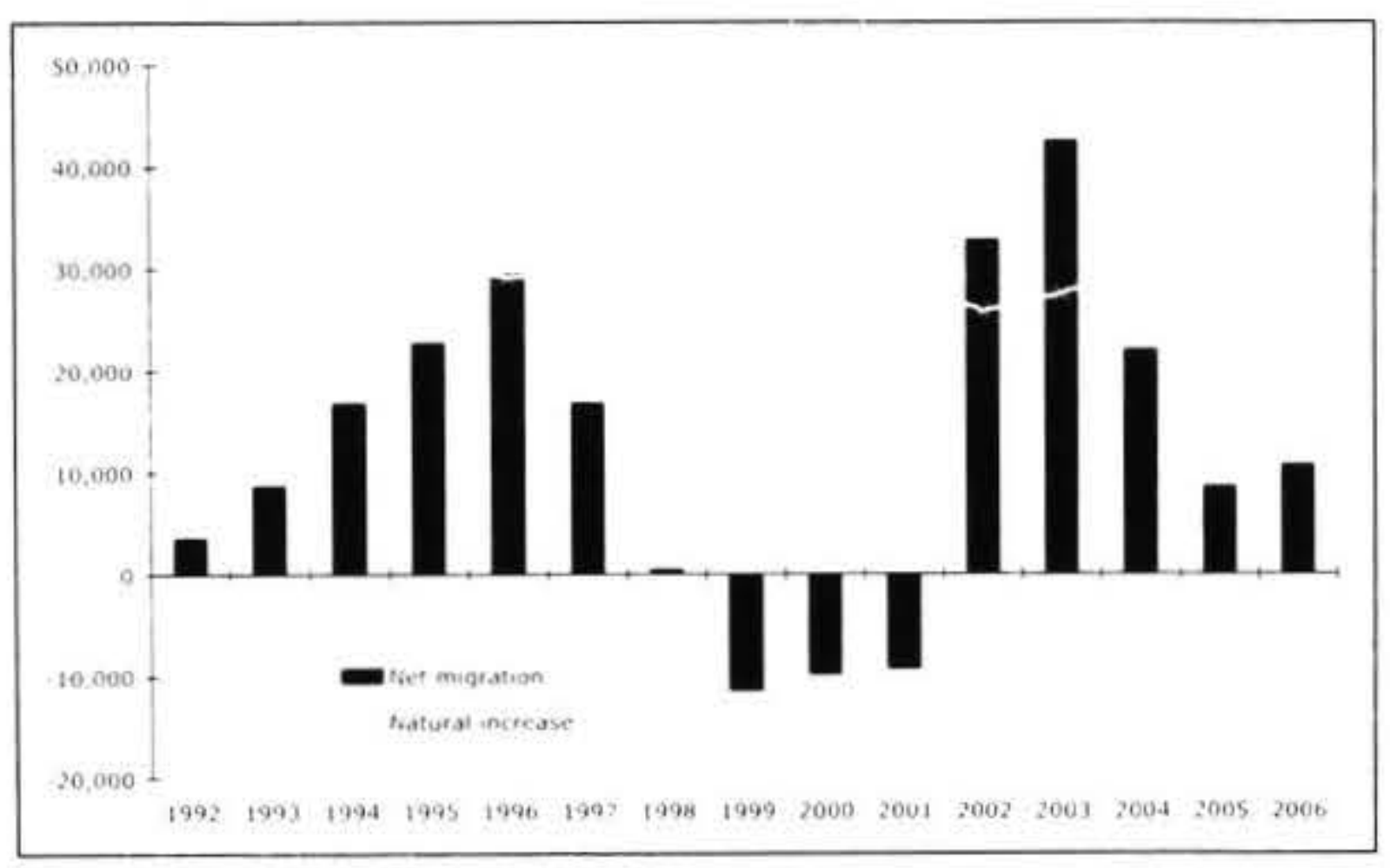

Source: Statistics New Zealand

The working age population has grown faster than the total population reflecting the combined effect of social trends and the ongoing impact of the baby boom generation. The social trends include a reduction in female fertility as fewer women choose to have children and those that do, tend to have fewer children and have them at a later stage in life.

The impact of the baby boom generation has been felt as a 'baby blip' as a concentration of older baby boom women started having children. The net effect has been an expanding proportion of the population in the working age group ( 15 years and over).

Statistics New Zealand expect this effect to continue with their mid range population projections showing the working age population as a proportion of the total population rising from $78.7 \%$ in 2006 to $82.8 \%$ in 2026 and $84.4 \%$ in 2051 . Most of the increase in the working age population will be in the older age brackets. The percentage of the working age population aged 40 an over will increase from around $55.9 \%$ in 2004 to $62.5 \%$ in 2026 and $67.6 \%$ in 2051 .

\section{Participation}

The main measure of attachment to the labour market is the labour force participation rate - the ratio of people in the labour force (those people in employment and those actively seeking and available for work) to the civilian population aged 15 years and over (Figure 3 ).

\section{Figure 3: Participation and Unemployment Rates.}

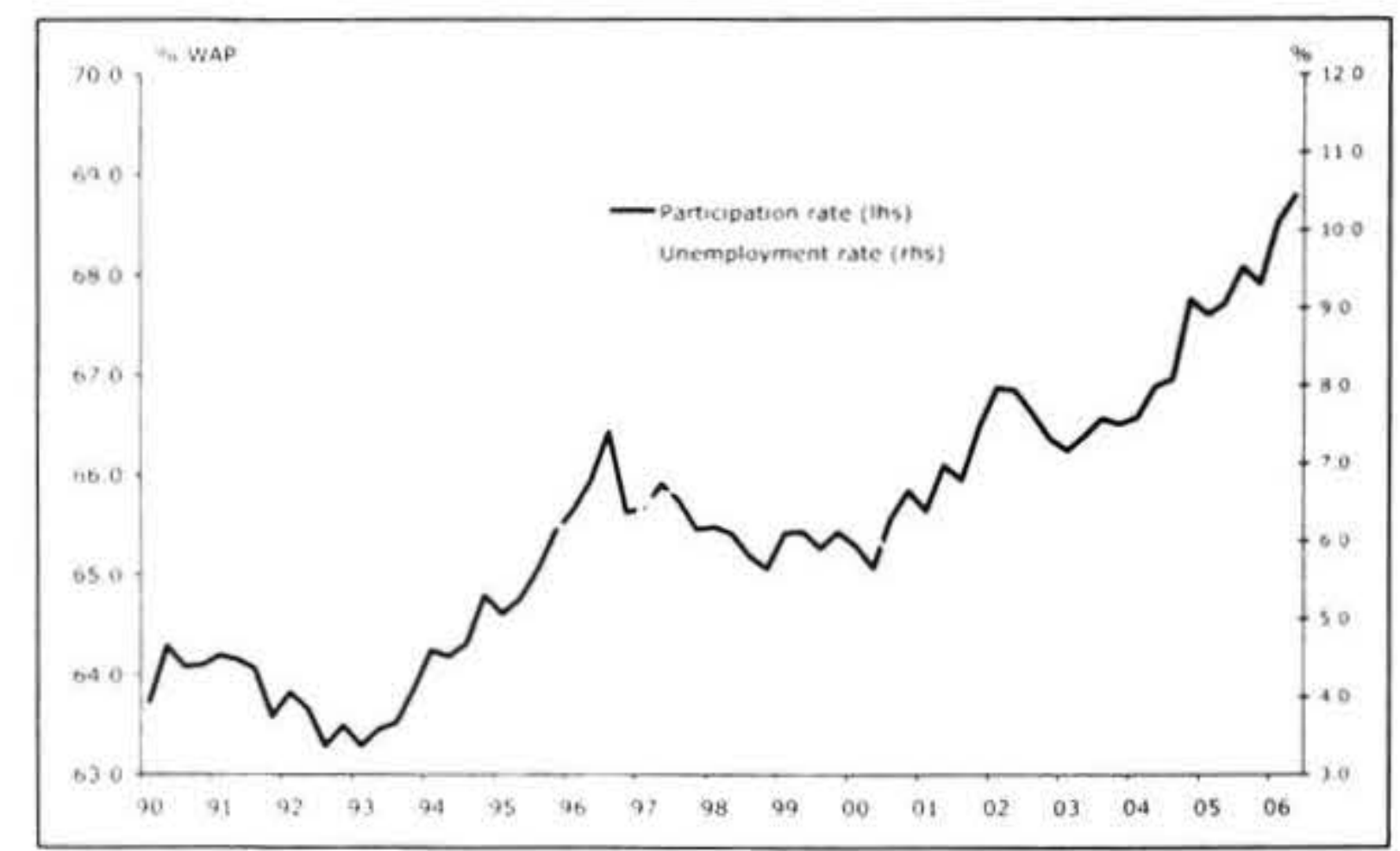

While the working age population has been growing faster than the total population, the size of the labour force has also been increasing at a faster pace than the working age population as the participation rate has pushed to all time highs. This reflects the combined effects of: strong demand for labour (peoples willingness to work and willingness to look for work increase when the demand for labour is high and the prospects of success are positive); increased participation by women; increased participation of older people; and a growing proportion of the population in 'prime' working ages.

Looking forward, the scope to further increase labour participation levels appears limited. Although, having said that, the factors that have been driving rising participation for women and older people are still at work and there remain pockets of groups people such as recent immigrants, Pacific Peoples and people with a disability who still have relatively low participation rates. 
Decisions to participate in paid or unpaid employment and tradeoffs between work and leisure are inherently personal ones. However, government policies can and do influence these choices. Policy measures and societal changes that strengthen the capacity to participate through improved education and health; improve the balance of incentives to shift from welfare-to-work; remove artificial incentives to retire or remain outside the workforce (for example, childcare subsidies, paid maternity and parental leave), and policies that enhance the flexibility of working arrangements and business practices could well support higher participation rates.

\section{Unemployment}

While the labour force has grown strongly it has not expanded at the same pace as the recent growth in demand for labour so the unemployment rate has fallen. The unemployment rate fell to just $3.6 \%$ in the June 2006 quarter, and remains low at $3.8 \%$ in the September 2006 quarter (Figure 3). Long-term unemployment is also very low with less than $20 \%$ of the unemployed in $\mathrm{New}$ Zealand having been unemployed for more than 26 weeks, so a much higher share of unemployment is now frictional (people moving between jobs).

There has also been a significant improvement in other 'wider' measures of unemployment. The number of jobless people (those who are either officially unemployed, or available but not actively seeking work, or actively seeking work but not available) has fallen to under $5 \%$ of the working age population with the number of discouraged workers hitting an all time low of just 3,500 in the year to September 2006 .

The number of underemployed people (those employed part-time who would like to work more hours) also serves as another measure of under-utilisation of labour in the economy. Of those people employed part-time in the year to September 2006 just $15.7 \%$ indicated a preference to work more hours. This compares with nearly $30 \%$ in the year to September 1999.

Some groups still suffer from moderately high rates of unemployment, for example, Maori at $8.0 \%{ }^{3}$ and those without qualifications at $5.8 \%$, despite large falls in recent years. Some further sub-groups suffer from very high unemployment rates, such as Maori aged 15-19 years $(24 \%)$ and others enjoy very low unemployment rates, such as Europeans $(2.7 \%)$.

\section{Labour Demand}

There is a strong relationship between growth in gross domestic product and several labour market indicators such as employment and the number of hours worked, with a one or two quarter lag between the two (Figure 4). This occurs due to the link between the demand for labour and the demand for goods and services in the economy. When demand for goods and services in the economy is strong, firms attempt to meet this demand by producing more output. In order to achieve this increase in production a firm may increase its labour input either in terms of hours worked or the number of people employed.

\section{Figure 4: Economic Growth and Labour Demand.}

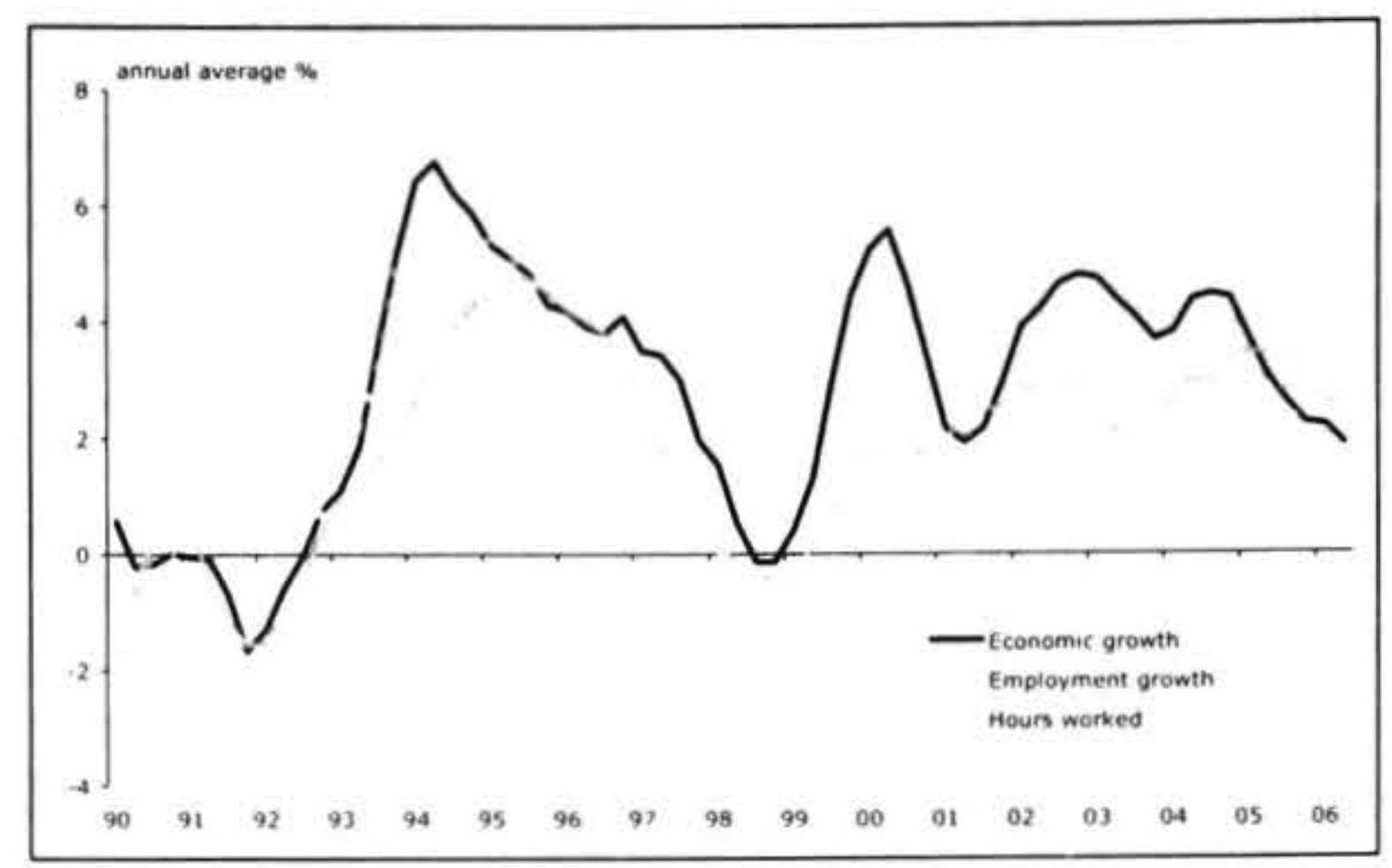

Source: Statistics New Zealand

This section looks at the labour input that is actually employed and the number of hours worked by people in employment. Unmet labour demand is captured through statistics on vacancies and business opinion surveys.

\section{Employment}

The number of people employed has grown by over 340,000 in the last seven years. In the year to September 2006, even as economic activity has slowed, employment grew by 44,800 . Moreover, the employment gains have been entirely driven by full-time employment. $87 \%$ of the increase in employment since September 1999 has been full-time ( 30 hours or more per week).

Commensurate with the rise in participation of women, female employment has increased strongly. Over the last decade female employment has grown by an average $2.2 \%$ per annum, compared to an average $1.7 \%$ per annum growth in male employment (Figure 5).

Figure 5: Employment by Gender.

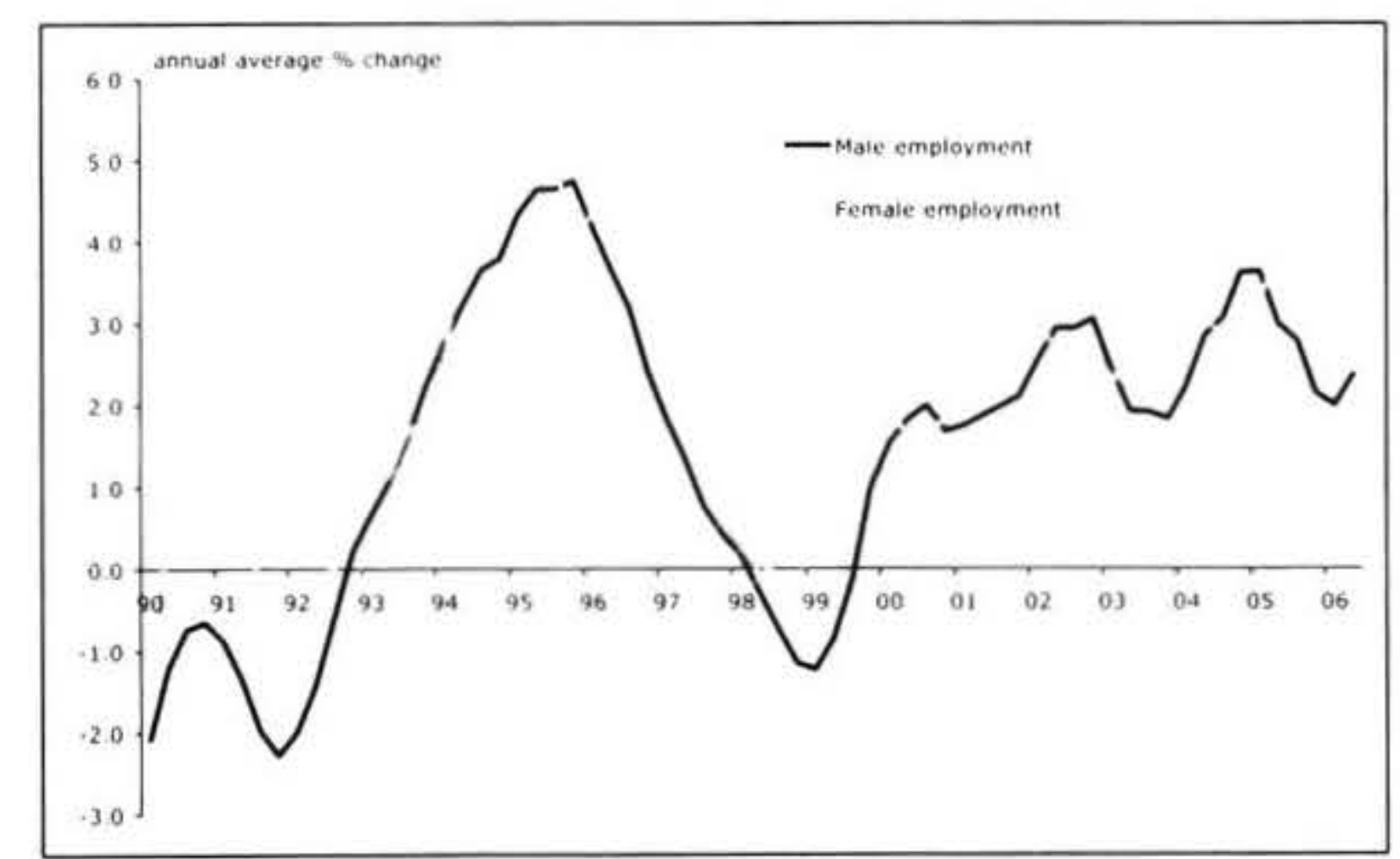

Source: Statistics New Zealand 


\section{Hours Worked}

As mentioned earlier, employers may vary the labour input to their production process by adjusting the number of hours that employed people work. In the short run a firm is more likely to respond to changes in the demand for its product by adjusting hours worked rather than the number of employed people.

Average hours worked per worker have remained fairly steady at around 35 hours over the past 20 years (Figure $6)$, although tending to fall more recently. This apparent stability hides a considerable shift. There was an increased diversity of working hours up until 1998, with high growth in part-time work (less than 30 hours) balanced by high growth in long hours ( 50 plus).

\section{Figure 6: Average Hours Worked.}

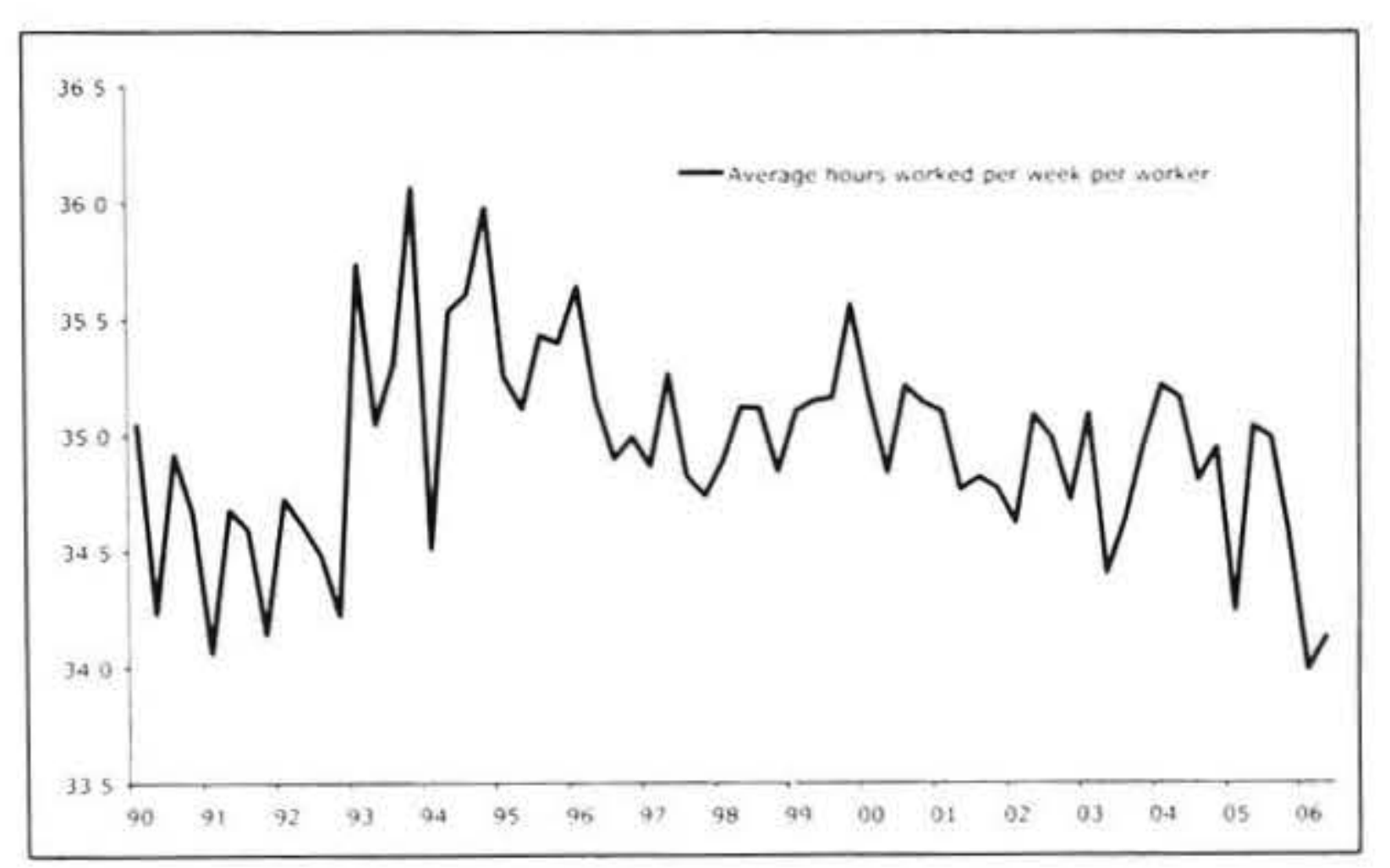

Source: Statistics New Zealand

The last seven years have seen a partial reversal of the trend towards shorter and longer hours as almost three quarters of all employment growth has been among people working 30-49 hours a week (Figure 7). The lower recent growth in long working hours may partly reflect strong growth among paid employees (up $22 \%$ since 1999), as opposed to self-employed (up $6 \%$ since 1999), who tend to work longer hours.

\section{Figure 7: Working Longer?}

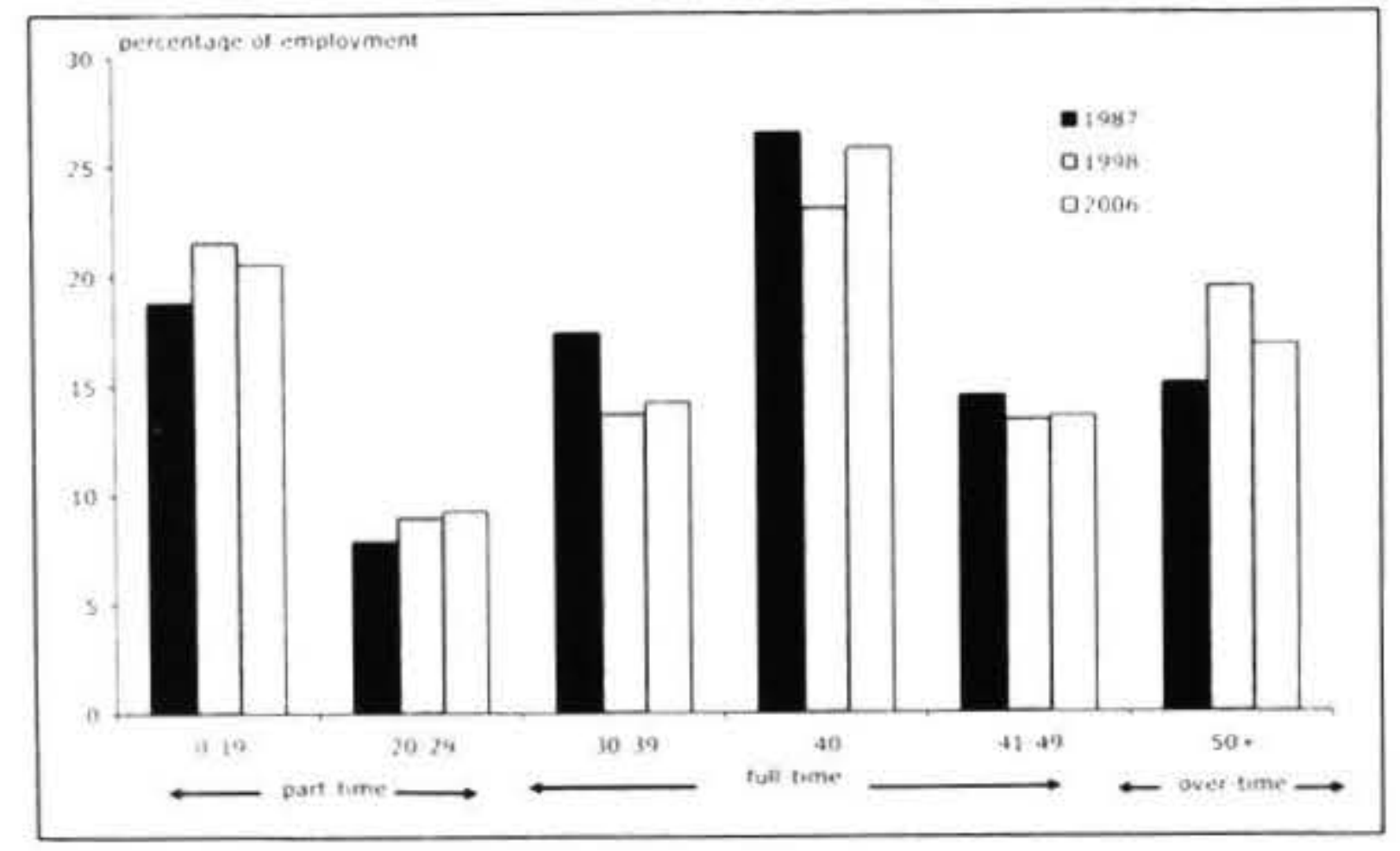

Soure: Statistics New Zealand
The fall in average hours worked per worker (to 34.2 in the year to September 2006), may indicate labour hoarding by firms (hours are easier to adjust than the number of workers) or increased work/life balance (people substituting work for more leisure, older workers scaling back hours instead of fully retiring). Work-life balance remains an important policy consideration, however, as a higher proportion of people are in work than ever before and about a fifth of employed people still work for 50 hours or more a week. Further, these figures do not pick up the advent of new technologies that can act to extend the working week beyond the workplace.

\section{Skills and Skill Shortages}

Numerous studies have identified the positive links between investment in education and the increased utilisation and productivity of labour. If we improve the education, skills and training of the labour force (increased quality) we can command higher prices for our products and increase the returns to working (wages).

Since the mid-1980s the proportion of the working-age population without qualifications has dropped from $42 \%$ to $26 \%$, a figure which is more typical of developed nations. Many more people now have school and postschool qualifications, including almost half of those employed, suggesting we now have a more skilled workforce. Notwithstanding these gains, many people in the workforce appear to have relatively low foundation skills.

A desirable trend has been workers moving into higher paid forms of work. More workers are moving into highly-skilled jobs and service oriented jobs and fewer into lower-skilled and primary sector jobs. Between the years to September 1999 and 2006, employment has grown strongly in the service and construction sectors. In terms of skill sets required, employment growth has been strongest in highly-skilled and skilled occupations.

However, we know the fastest growing occupations in New Zealand today are not just computer engineers and management consultants but also restaurant service workers, salespeople and professional care workers. While the economic and social benefits of investment in education are not disputed we caution that human capital accumulation on its own is not a sufficient condition for growth. It is also important that the skills of the individuals match the demand from firms and the structure of the economy.

As a consequence of the rapid growth in employment the ability of employers to find skilled and unskilled staff became progressively more difficult since the beginning of 1999. By late 2004 the shortage of skilled labour as measured by the Quarterly Survey of Business Opinion (QSBO) reached a record high since measures began in 1975. The shortage of unskilled labour peaked in early 2005 (Figure 8). Around this period about a quarter of firms regarded the shortage of labour as the largest constraint on their expansion. 
Figure 8: Skill Shortage?

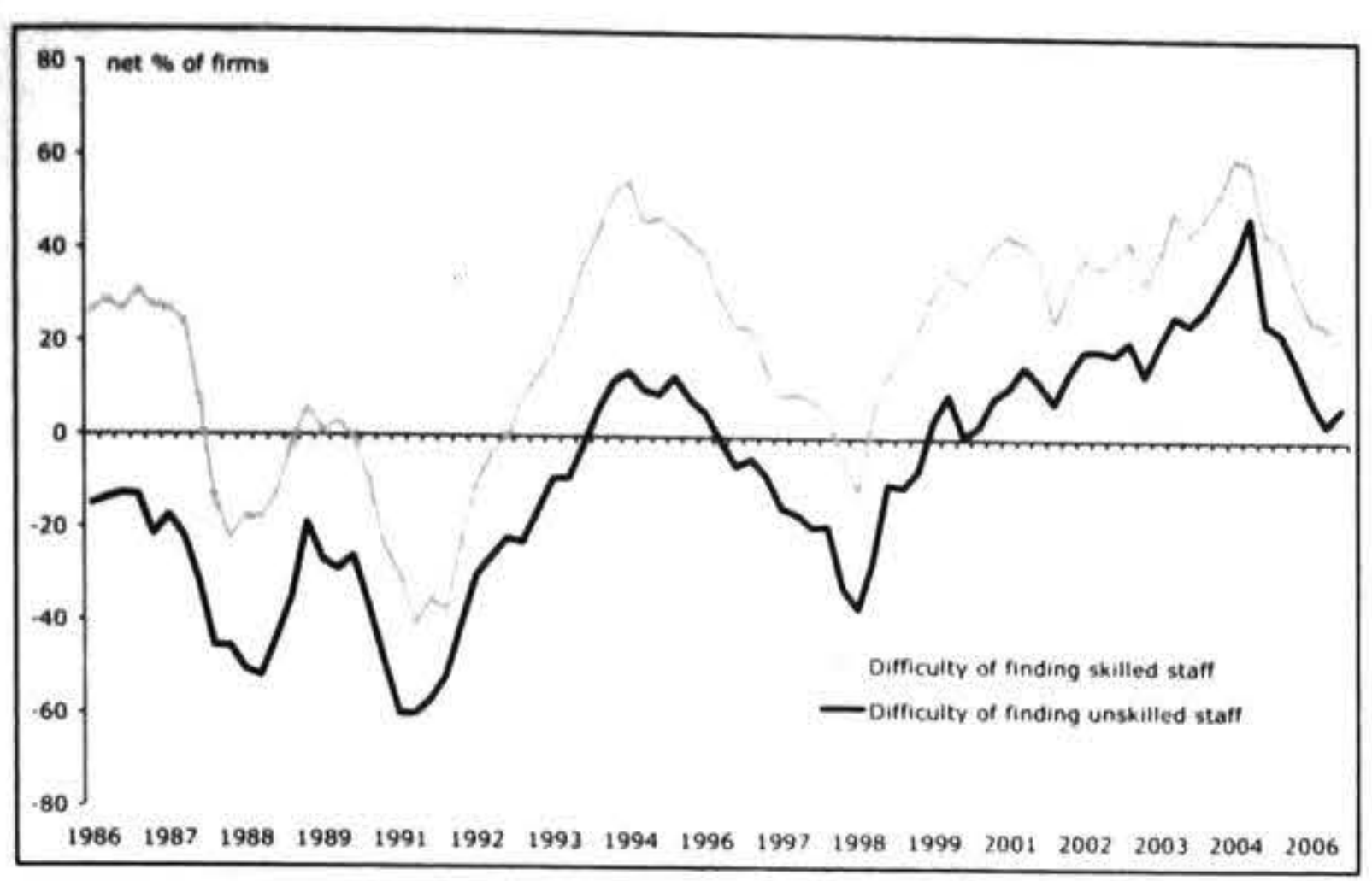

Source: Quarterly Survey of Business Opinion

\section{Vacancies and Employment Intentions}

The easing in skill shortage indicators since 2005 has also been matched by other more recent signs of an easing in the tightness of the labour market. Vacancies provide a useful insight into employers' behaviour and can act as an indicator of changes in employers' perceptions of economic conditions or outlook. The Department of Labour's measure of job advertising, the job vacancy index, has been on a downward trend since March 2005.

\section{Figure 9: Demand for Labour Eases.}

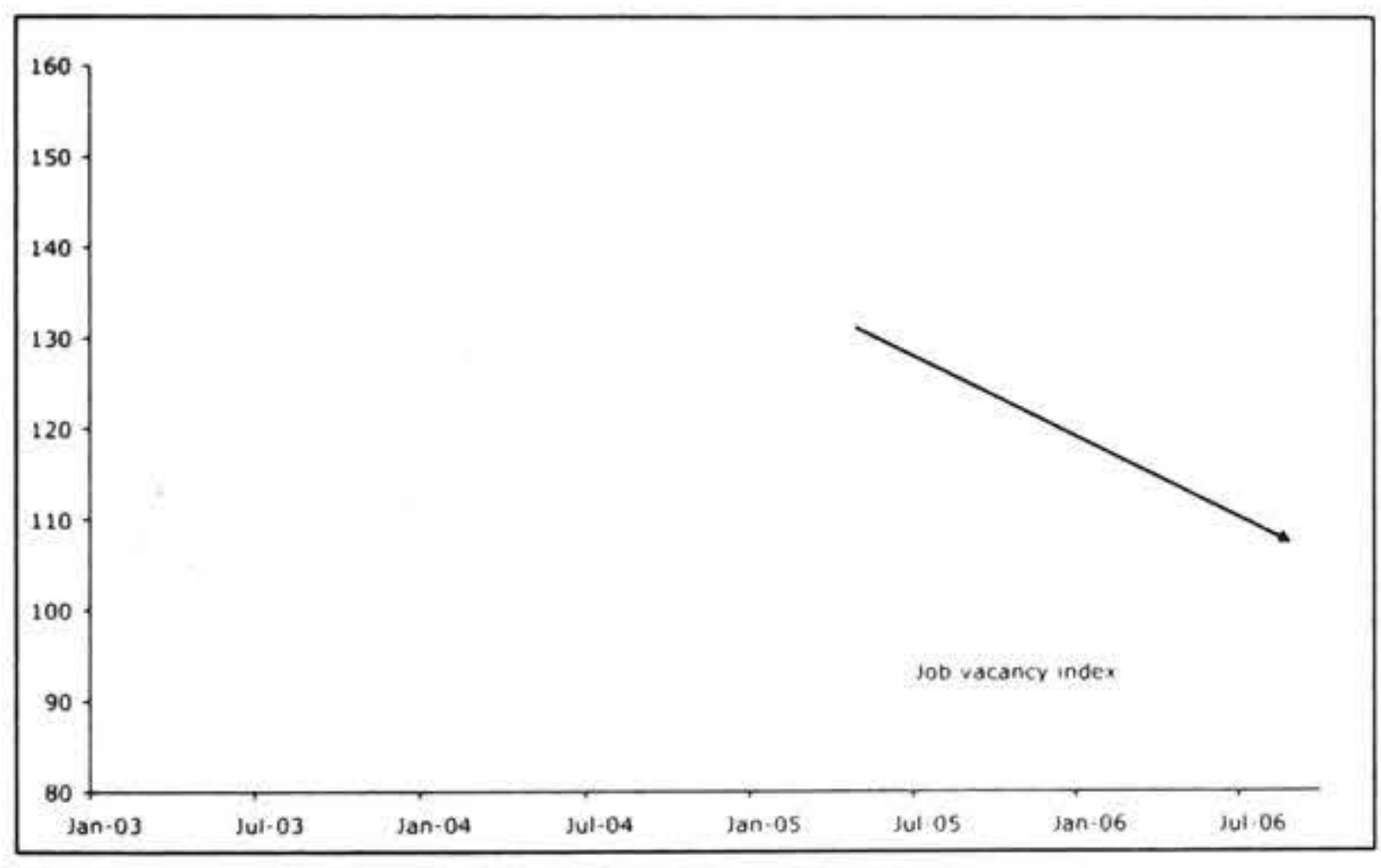

Source: Department of Labour JVMP

Another sign that labour market conditions have eased in recent months is the fall in labour turnover reported by QSBO respondents since the beginning of 2005. Workers are less likely to leave employment when job prospects worsen, so the decline in labour turnover is often interpreted as indicating a reduction in job opportunities.

Although this evidence suggests that labour market conditions are not as tight as they were in early 2005 , the New Zealand labour market remains in a healthy state. The amount of labour turnover reported by QSBO respondents remains well above the level reported in previous economic downturns (for example, in the early and late 1990s). The situation is similar for the reported ease of finding labour. There are also signs that employment intentions are on the rise. In October 2006, the National Bank's Business Outlook reported a net $6 \%$ of firms expecting to increase staff, from the $1 \%$ in September expecting to decrease. That is the highest in eighteen months and back up to around the long-term norm. The comparable employment outlook in the QSBO also jumped to a net positive $6 \%$. This was above its historical average of minus $2 \%$.

\section{Rising Costs of Employing People}

There is a close correlation between skill shortages and wage growth, with typically a lag of four to five quarters between the two measures. In response to the shortage of skills and labour, wages have risen across the economy. Annual average wage increases appear to have peaked at around $5.5 \%$ (as measured by the experimental, unadjusted Labour Cost Index - our preferred measure of nominal wage inflation), just over a year after skill shortages peaked.

While workers have enjoyed strong growth in nominal wages, pushing up unit labour costs, real wages (adjusted for consumer price inflation) have been growing in line with productivity increases, suggesting little change in real unit labour costs.

\section{Figure 10: Risings Wages and Labour Costs.}

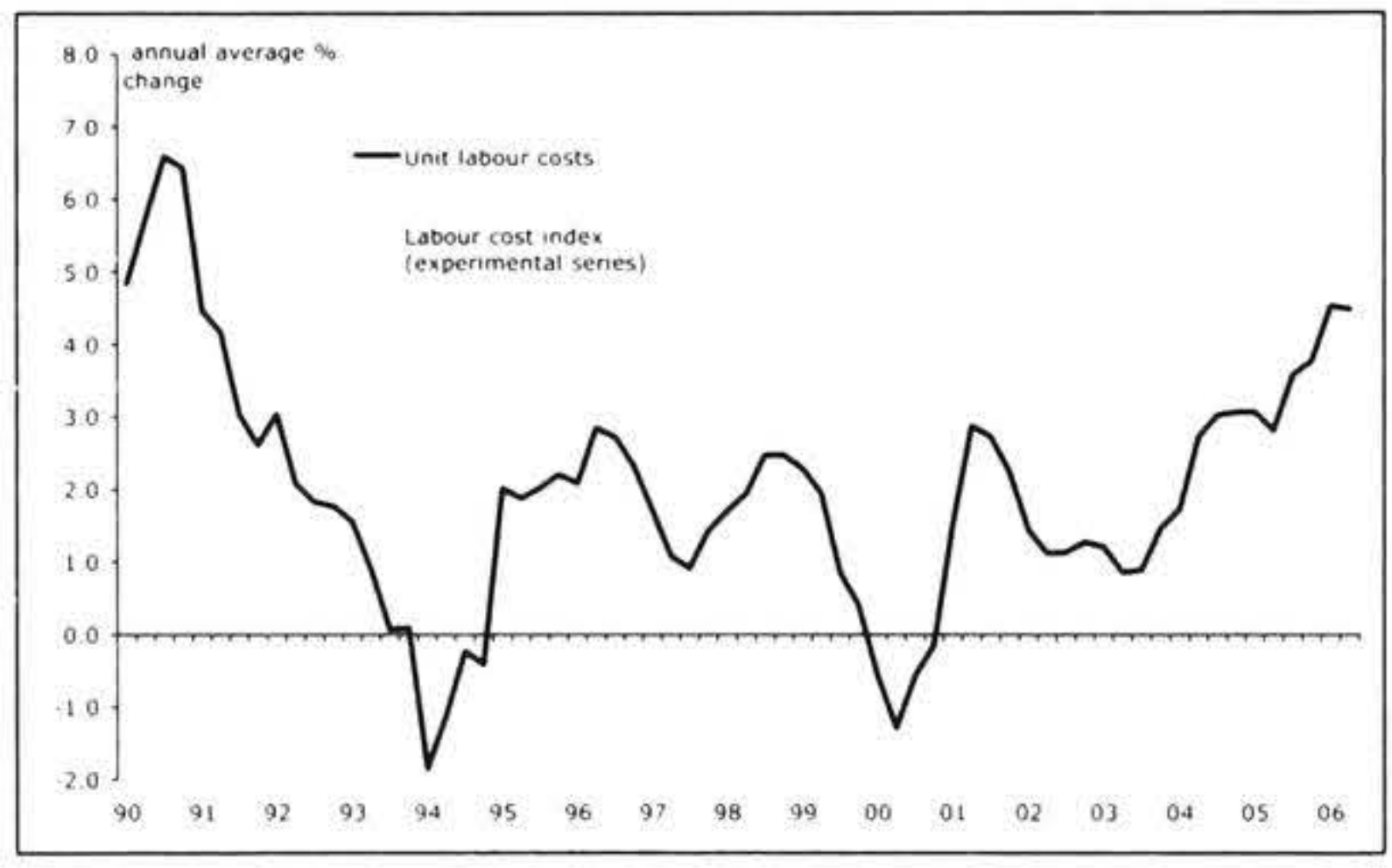

Source: Statistics New Zealand, DoL Calculations

The proportion of firms increasing salary and wage rates remains at relatively high levels, with $21 \%$ reporting increases of more than $5 \%$ in the year to September 2006 . The number of businesses increasing overtime wage rates has eased slightly to around $63 \%$, suggesting a marginal easing in wage pressure.

Strong wage growth is also reflected in an increase in labour's share of national income. National accounts data shows that compensation of employees (wages) rose from $41.5 \%$ of GDP in 2002 to $42.7 \%$ in 2005 , consistent with a steady improvement in workers' bargaining power.

In this environment we expect to see businesses continue to look for ways to improve productivity by adding value by increasing investment and investing in research, education and training. It will also provide employees with the incentive and scope to increase the use of nonwage benefits in compensation packages. 


\section{Productivity}

Labour productivity measures the economy's output in relation to its labour input. We can disaggregate labour productivity into three kinds of change: changes in the ratio of capital to labour (capital deepening); changes in the composition (or quality, both in terms of education and health) of labour, ${ }^{+}$and changes in multi-factor productivity (MFP).

It is sometimes easiest to think of MFP as the 'residual', that is, all labour productivity growth that is not attributable to capital deepening or gains in labour quality. It is often described as a measure of the effects of technical progress but this can be somewhat misleading as it can also include a host of other factors such as changes in employment arrangements and condtions, business practices, enterprise, innovation and competition.

In March 2006 Statistics New Zealand released New Zealand's first official productivity statistics. Separate series were produced for labour productivity. capital productivity and MFP. However, the new series do not cover the entire economy: the scope has been confined to a subset of the economy termed the 'measured sector'. The 'measured sector', consists of industries for which estimates of inputs and outputs are independently derived and which have both labour and capital inputs." Excluded are those industries - mainly (but not entirely) government non-market industries whose services, such as administration, health and education, are provided free or at nominal charges and whose output is measured in the national accounts largely using input methods, such as numbers of employees.

Figure 11: Labour Productivity Growth.

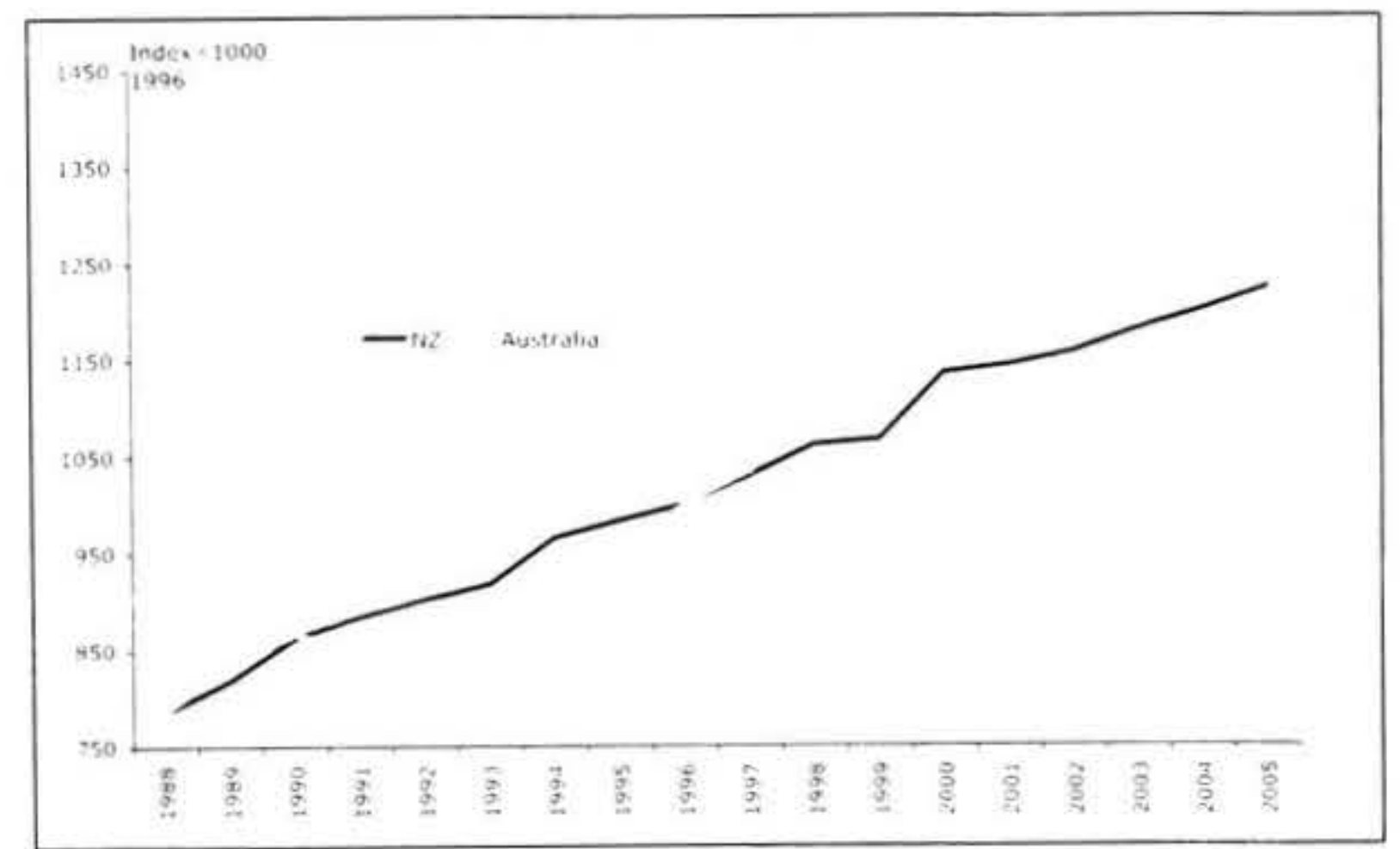

Source; Statistics New Zealand

Labour productivity (the amount of output produced for each hour of paid work) in the measured sector grew by $2.6 \%$ per annum from 1988 to 2005 . This is slightly higher than growth of $2.3 \%$ in Australia, the only other country with strictly comparable statistics. Despite this narrowing of the gap, the amount of output produced for each hour of work in New Zealand remains well below that in Australia and the OECD average.
Labour productivity in New Zealand using the new measures grew by $1.5 \%$ per annum from 2000 to 2005 , down from growth of $2.9 \%$ in the previous five years. This shows us that labour productivity growth does not necessarily always go hand in hand with other measures of economic well-being. Between 1988 and 1993, high labour productivity growth resulted from fewer hours of work producing a relatively constant level of output. Labour productivity growth between 2000 and 2005 was lower than in the previous five years, but there was strong growth in labour input and in overall output.

\section{Demand and Supply}

The fall in long-term unemployed, underemployment and discouraged job seekers along with the substantial fall in the unemployment rate over recent years (to below the generally estimated NAIRU) appears to point to a positive structural shift in the labour market. Evidence of a possible structural shift is also shown by the change in the relationship between the unemployment rate and the degree of difficulty in finding staff. Over the past 12 months that relationship has changed - despite the unemployment rate remaining low, the difficulty of finding labour (both skilled and unskilled) has eased (Figure 12).

\section{Figure 12: Better Matching?}

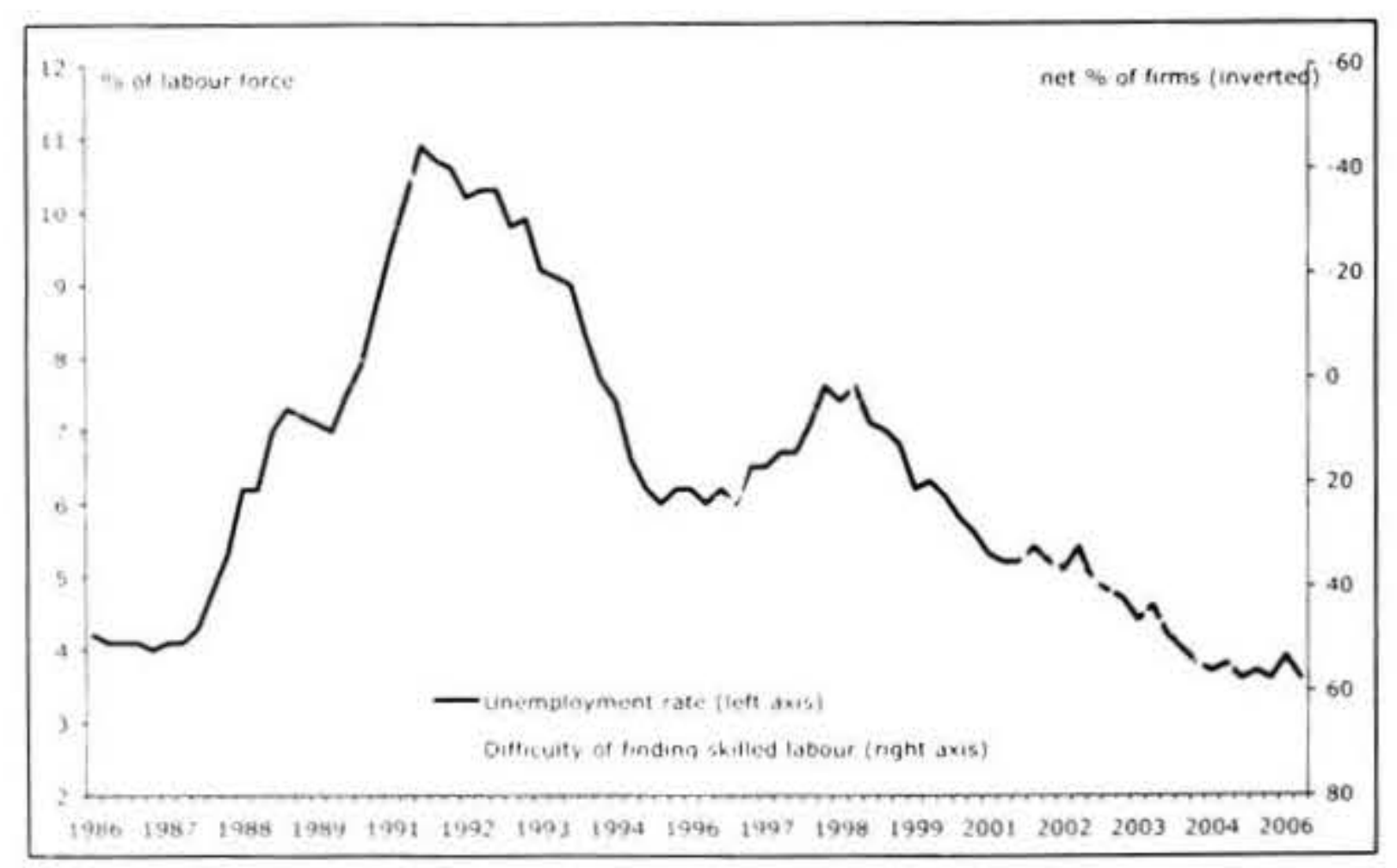

Source: Statistics New Zealand, NZIER

Although pin pointing the explicit reasons behind a structural shift is a rough and ready exercise, we can list a number of possible factors. We are interested in changes that are both substantial and long lasting. These include anything that systematically changes inflationary pressure in the economy at a given level of unemployment and will include such things as:

- the industrial relations system (for example, changes in the power of trade unions, the characteristics of the collective bargaining agreements and the wage-setting mechanisms);

- the benefit system and its interface with the labour market;

- active labour market policies including things such as better targeted employment services and training 
for employment in industries facing skill and labour shortages

- the increased use of non-wage benefits in compensation 'packages';

employment protection including legal requirements around job security and minimum wages;

- a more flexible labour market (for example, the growth of part-time work and the changing composition of the labour force $)^{7}$;

- a better match between the skill requirements of job vacancies and the available skills of unemployed job seekers and the skills available in the wider labour market.

Several factors could account for this improved match. Firstly, an immigration policy that has become increasingly responsive to the needs of the labour market through the issue of temporary work permits to fill skill gaps, a new seasonal work policy that has enabled employers to fill seasonal jobs with imported labour and increasing the importance of a job offer as a selection criterion for residency under the Skilled Migrant Category. Secondly, industry training which is directly driven by the skill needs of industry has resulted in a significant up-skilling of the workforce. Thirdly, sectoral and regional engagements which bring together industry and business organisations, unions and training and education providers to identify solutions to skill shortages and encourage a closer match between industry needs and the provision of education and training.

\section{Conclusion}

The New Zealand labour market seems to have reached a new position of high participation and low unemployment after six years of strong and sustained economic growth.

With labour supply stretched close to the limit it appears that labour demand is going to keep substantial pressure on available labour for the foreseeable future. Although there will be some easing in the short term due to a cyclical downturn, this means the labour market is expected to remain tight with low unemployment and persistent skill and labour shortages.

There are numerous challenges ahead if we want to be able to maintain the gains we have made in labour utilisation while raising the level and growth rate of labour productivity. These include a continued focus on:

- developing a more comprehensive and responsive skills base, including raising foundation skills alongside top-end skills such as improving the quality of leadership and management skills;

ensuring people have real choices to work, as well as promoting work-life balance; raising workplace productivity through increased investment, improving the way work is organised in firms, creating workplace practices that encourage innovation and those that develop, attract and retain staff, creating a culture of networking and collaboration; and

ensuring effective transitions for people between periods of paid, unpaid work and education/training and matching and facilitating the movement of redundant workers to new jobs.

\section{Future Research}

This overview touches on a number of areas where further research could make a valuable contribution to our understanding of the forces driving change in the New Zealand labour market.

We are particularly interested in research aimed at understanding the dynamics of productivity growth at a national and firm level. For example: (1) analysing the links between firm productivity and employment practices (such as training and flexible working arrangements), business practices, innovation and ICT use. (2) Looking at what is being done within firms to stimulate workplace changes and raise productivity. (3) Research on the main factors that encourage, or discourage, New Zealand firms to transform from low skill, low wage, low-value added businesses to high skill, high wage, high-value added businesses and what helps them succeed in doing this.

So far policy has tended to focus largely on the supply of skills - concerned mainly with the introduction of measures to enhance the volume and quality of skilled workers in the labour force - either those entering the labour force for the first time, those already in the labour force, or attracting back into the labour force those that have left. However, our knowledge on the interaction between skills and productivity has suffered because of a lack of information on the demand-side. Exploring the pattern of the demand, the use, and the development of skills in New Zealand firms would provide a rich and valuable balance to the research on the supply of skills in the labour market. ${ }^{.}$

\section{Notes}

I A large influx of workers can actually slow productivity growth as newly engaged workers take time to up-skill and contribute fully to the economy. However, over the medium term a greater attachment to the labour force will tend to raise productivity through the process of upskilling and new training opportunities.

2 Labour force participation rates vary with age with the highest rates usually occurring between the prime ages of 35-49 - after people have finished studying/training and raising (young) children and before they begin to retire. 
All figures in this paragraph refer to year to September 2006.

In practice, measurement issues mean it can be difficult to isolate changes in the quality of labour and hence they are often captured in Multi-factor productivity.

See: $\quad$ http://www.stats.govt.nz/products-and -services/info-releases/productivity-statistics.htm

Note that the Statistics NZ 'measured sector' is identical in coverage to the productivity statistics published by the Australian Bureau of Statistics who use the term 'market sector' for this grouping. The measured sector excludes the following Australia New Zealand Standard Industrial Classification (ANZSIC) divisions: L: Property and Business Services, M: Government Administration and Defence, $\mathrm{N}$ : Education, $\mathrm{O}$ : Health and Community Services and Q: Personal and Other Services

That is, a change in the skill base, ethnic composition, age and gender structure of the labour force.

See, for example, SriRamaratnam, Ram: Zhang, Kevin; Whiteford, Andrew "Forecasting in the Labour Market." in this volume

\section{References}

Job Vacancy Monitoring Programme, Job Vacancy Monitor, Department of Labour www.dol.govt.nz/publications/jvm/job-ad-monthly -report.asp

Department of Labour, Workplace Productivity Agenda http://www.dol.govt.nz/workplaceproductivity/

National Bank, Business Outlook

www.nbnz.co.nz/economics/outlook/NBNZ_Business _ Outlook_Data.xls

New Zealand Institute of Economic Research, Quarterly Survey of Business Opinion

\section{Reserve Bank of New Zealand}

www.rbnz.govt.nz/monpol/statements/sep04.pdf

\section{Statistics New Zealand}

www.stats.govt.nz

\section{The Treasury}

www.treasury.govt.nz

\author{
Author \\ Joselyn Stroombergen \\ Senior Analyst \\ Labour Market Dynamics \\ Work Directions \\ Department of Labour \\ P.O. Box 3705 \\ Wellington \\ Joselyn.Stroombergen $a$ dol.govt.nz
}

